\title{
A heart team's perspective on interventional mitral valve repair: Percutaneous clip implantation as an important adjunct to a surgical mitral valve program for treatment of high-risk patients
}

\author{
Hendrik Treede, MD, ${ }^{\mathrm{a}}$ Johannes Schirmer, MD, ${ }^{\mathrm{a}}$ Volker Rudolph, MD, ${ }^{\mathrm{b}}$ Olaf Franzen, MD, ${ }^{\mathrm{b}}$ \\ Malgorzata Knap, MD, ${ }^{\mathrm{b}}$ Michael Schluter, PhD, ${ }^{\mathrm{b}}$ Lenard Conradi, MD, ${ }^{\mathrm{a}}$ Moritz Seiffert, MD, ${ }^{\mathrm{a}}$ \\ Dietmar Koschyk, MD, ${ }^{\mathrm{b}}$ Thomas Meinertz, MD, ${ }^{\mathrm{b}}$ Stephan Baldus, MD, ${ }^{\mathrm{b}}$ and \\ Hermann Reichenspurner, MD, $\mathrm{PhD}^{\mathrm{a}}$
}

\begin{abstract}
Objective: Surgical mitral valve repair carries an elevated perioperative risk in the presence of severely reduced ventricular function and relevant comorbidities. We sought to assess the feasibility of catheter-based mitral valve repair using a clip-based percutaneous edge-to-edge repair system in selected patients at high surgical risk with mitral regurgitation grade 3 or worse.
\end{abstract}

\begin{abstract}
Methods: Between 2002 and January 2011, 202 consecutive patients without prior mitral valve surgery (age $75 \pm$ 9 years; $63 \%$ were male) with symptomatic functional (65\%), degenerative (27\%), or mixed $(8 \%)$ mitral regurgitation were treated with a percutaneous clip system for approximation of the anterior and posterior mitral leaflets. Risk for mitral valve surgery was considered high in terms of a mean logistic European System for Cardiac Operative Risk Evaluation of $44 \%$ (range, $21 \%-54 \%$ ). Preprocedural left ventricular ejection fraction was $35 \%$ or less in $36 \%$ of patients. An interdisciplinary heart team of cardiologists and cardiac surgeons discussed all patients.

Results: Percutaneous clip implantation was successful in 186 patients (92\%). Patients were treated with 1 clip $(\mathrm{n}=125 ; 62 \%), 2$ clips $(\mathrm{n}=64 ; 32 \%)$, or 3 or more clips $(\mathrm{n}=7 ; 3 \%)$. Reduction in mitral regurgitation from pre- to postprocedure was significant $(P<.0001)$ and remained stable within the first 12 months in the majority of patients. Thirty-day mortality was 3.5\% (7/202 patients). Hospital stay was $12 \pm 10$ days, and median intensive care unit stay was 1 day (range, $0-45$ days). Eleven patients required surgical valve repair/replacement at a median of 38 days ( $0-468$ days) after percutaneous clip implantation.
\end{abstract}

Conclusions: Clip-based percutaneous mitral valve repair is a safe, low-risk, and effective therapeutic option in symptomatic patients with a high risk for surgery and does not exclude later surgical repair. (J Thorac Cardiovasc Surg 2012;143:78-84)

Surgical mitral valve repair (MVR) is the gold standard treatment for severe mitral regurgitation (MR) in degenerative disease and has superseded mitral valve replacement as the treatment of choice in the majority of patients in the United States and Western Europe. In experienced centers, surgical MVR can be performed with approximately $0 \%$ mortality and extremely low complication rates. ${ }^{1}$ Successful surgical MVR in patients with preserved ventricular function restores quality of life and life expectancy and is

From the Departments of Cardiovascular Surgery ${ }^{\mathrm{a}}$ and General and Interventional Cardiology, ${ }^{\mathrm{b}}$ University Heart Center, Hamburg, Germany.

Disclosures: Dr Franzen serves as a consultant to Abbott Vascular. All other authors have nothing to disclose with regard to commercial support.

Drs Hendrik Treede and Johannes Schirmer contributed equally to this article.

Read at the 91st Annual Meeting of The American Association for Thoracic Surgery, Philadelphia, Pennsylvania, May 7-11, 2011.

Received for publication May 25, 2011; revisions received Aug 25, 2011; accepted for publication Sept 26, 2011; available ahead of print Oct 31, 2011.

Address for reprints: Hendrik Treede, MD, University Heart Center Hamburg, Department of Cardiovascular Surgery, 20246 Hamburg, Germany (E-mail: treede@uke.de).

0022-5223/\$36.00

Copyright (C) 2012 by The American Association for Thoracic Surgery

doi:10.1016/j.jtcvs.2011.09.033 therefore recommended as treatment even in asymptomatic patients if the likelihood of repair is high. ${ }^{2}$ In addition, the invasiveness of surgical MVR is favorably reduced if minimally invasive techniques through a right-sided lateral minithoracotomy are implemented as the standard of care. ${ }^{3}$

In functional mitral valve disease, however, the results of surgical MVR are worse and procedural risks are higher. ${ }^{4}$ If MR is caused by ventricular dysfunction (eg, dilated cardiomyopathy), repair of the valve may restore valve function but does not treat the underlying ventricular disease. Comorbidities such as renal dysfunction, previous cardiac surgery, and a history of stroke or myocardial infarction are common, thereby also increasing the risk of surgical treatment. With an aging population and improved medical therapy, the number of patients with functional MR and relevant comorbidities will further increase. The Euro Heart Survey revealed that patients with reduced ventricular function or significant comorbidities and patients aged more than 80 years were unlikely to be referred for mitral valve surgery at all. ${ }^{5}$ It is for this growing population of high-risk patients that less-invasive treatment alternatives have been explored. 


\section{Abbreviations and Acronyms \\ CABG = coronary artery bypass grafting euroSCORE $=$ European System for Cardiac Operative Risk Evaluation \\ EVEREST II = Endovascular Valve Edge-to- Edge Repair Study \\ MR = mitral regurgitation \\ MVR $\quad=$ mitral valve repair \\ NYHA $=$ New York Heart Association \\ TR $=$ tricuspid regurgitation}

Percutaneous MVR techniques currently have been developed for annuloplasty (direct or through a coronary sinus approach), left ventricular chamber remodeling, chordae replacement, or leaflet repair.

The MitraClip device (Abbott Vascular, Menlo Park, Calif) uses a steerable catheter to deliver 1 or more clips to the anterior and posterior leaflet via transseptal access. The procedure imitates the surgical technique previously described by Alfieri and colleagues, ${ }^{6}$ which connects the anterior and posterior mitral leaflets with a suture and thus creates a "double orifice" mitral valve, thereby reestablishing leaflet coaptation and reducing MR. The procedure has been described in detail. ${ }^{7,8}$

Because of the excellent surgical results of surgical MVR, MitraClip therapy is only performed in patients carrying a high surgical risk at the University Heart Center. A heart team consisting of interventional cardiologists, experienced mitral valve surgeons, and echocardiographers reviews every case and decides on the appropriate therapy. Figure 1 demonstrates a flow-chart on how treatment decisions are made by the heart team at the University Heart Center. The majority $(80 \%)$ of patients treated with the
MitraClip device would have fulfilled the exclusion criteria for the recently published Endovascular Valve Edge-toEdge Repair Study (EVEREST II) trial, ${ }^{9}$ a randomized comparison of surgical and interventional MVR using the MitraClip device, mainly because of severely reduced ventricular function in functional MR. Nevertheless, the number of patients presenting with severe MR and high surgical risk has markedly increased since the introduction of percutaneous techniques at the University Heart Center. This makes a change in referral policy obvious because we now see patients who had not been referred to the University Heart Center for MVR before.

We report on our results of percutaneous MVR using the MitraClip system in a consecutive series of 202 patients who were deemed high risk for surgical MVR. All procedures were performed in a hybrid operation theater by a dedicated team of cardiologists and cardiac surgeons. The primary objective of this analysis was to assess the efficacy of the MitraClip system in reduction of MR grade and functional patient improvement as expressed by New York Heart Association (NYHA) functional class.

\section{MATERIALS AND METHODS Patients}

From 2002 to 2010, a total of 1764 patients underwent isolated mitral valve operations and interventions at the University Heart Center, of whom 202 consecutive patients with a mean age of $75 \pm 9$ years (range, 47-93 years) were treated with the MitraClip system for approximation of the anterior and posterior mitral leaflet (September 2008 to January 2011). Severity of MR was graded in accordance with the American Society of Echocardiography guidelines. ${ }^{10}$ The majority of patients $(98.5 \%)$ presented with grade $3+$ or $4+$ symptomatic MR of functional $(65 \%)$, degenerative $(27 \%)$, or mixed $(8 \%)$ origin and underwent joint evaluation by an interdisciplinary panel consisting of cardiovascular surgeons and cardiologists. High surgical risk was based on logistic European System for Cardiac Operative Risk Evaluation (euroSCORE) calculation ${ }^{11}$ or the presence of severely reduced ventricular function or relevant comorbidities. The overall mean logistic euroSCORE was 36\% (range, 21\%-54\%).

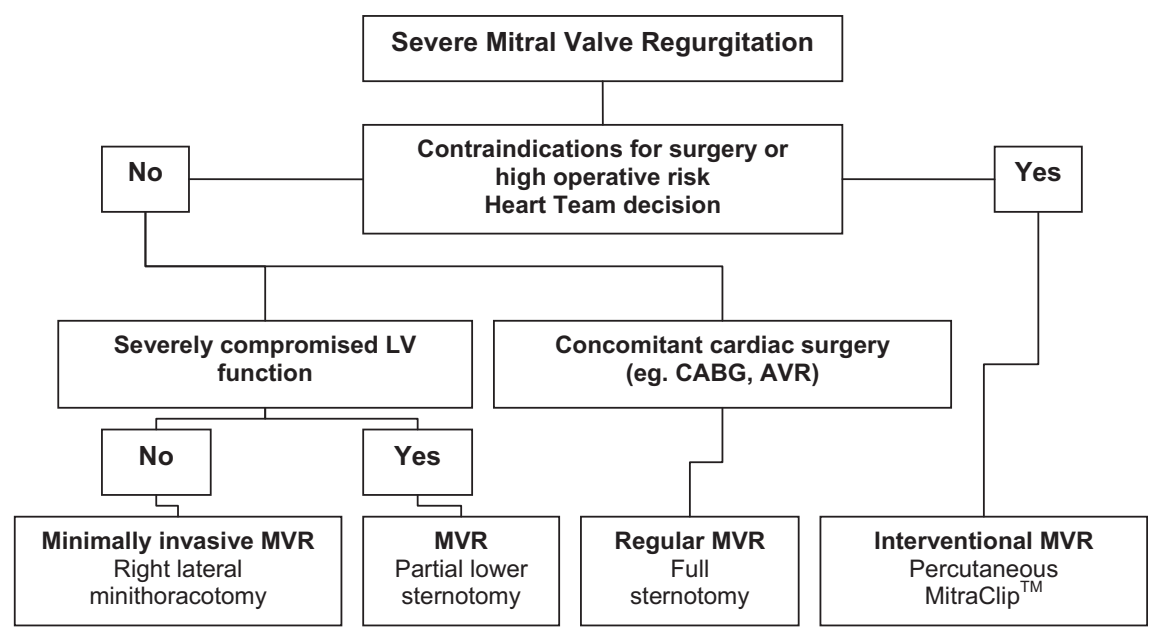

FIGURE 1. Flow-chart on Heart Team decisions in patients with severe MR at the University Heart Center Hamburg. AVR, Aortic valve repair; $C A B G$, coronary artery bypass grafting; $L V$, left ventricular; $M V R$, mitral valve repair. 
TABLE 1. Baseline patient characteristics

\begin{tabular}{|c|c|}
\hline $\mathrm{N}$ & 202 \\
\hline Age, y & $75 \pm 9$ \\
\hline Men, n (\%) & $127(63)$ \\
\hline Prior surgical MVR, n (\%) & $1(0.5)$ \\
\hline Logistic euroSCORE, $\%$ (range) & $36(21-54)$ \\
\hline Hypertension, $\mathrm{n}(\%)$ & $148(74)$ \\
\hline Hypercholesterolemia, n (\%) & $127(63)$ \\
\hline Diabetes, $\mathrm{n}(\%)$ & $71(35)$ \\
\hline Chronic obstructive pulmonary disease, $\mathrm{n}(\%)$ & $69(34)$ \\
\hline Renal failure, $\mathrm{n}(\%)$ & $104(52)$ \\
\hline Chronic heart failure, $\mathrm{n}(\%)$ & $169(84)$ \\
\hline Atrial fibrillation, $\mathrm{n}(\%)$ & $129(64)$ \\
\hline Coronary artery disease, $\mathrm{n}(\%)$ & $145(72)$ \\
\hline Prior CABG, $\mathrm{n}(\%)$ & $70(35)$ \\
\hline \multicolumn{2}{|l|}{ Cardiomyopathy, n (\%) } \\
\hline Ischemic & $82(41)$ \\
\hline Dilated & $54(27)$ \\
\hline Valvular & $9(5)$ \\
\hline \multicolumn{2}{|l|}{ MR cause, $n(\%)$} \\
\hline Functional & $131(65)$ \\
\hline Degenerative & $55(27)$ \\
\hline Mixed & $16(8)$ \\
\hline \multicolumn{2}{|l|}{ MR severity, n (\%) } \\
\hline $2+($ mild to moderate $)$ & $3(1.5)$ \\
\hline $3+($ moderate to severe $)$ & $107(53)$ \\
\hline $4+($ severe $)$ & $92(46)$ \\
\hline \multicolumn{2}{|l|}{ NYHA functional class, $\mathrm{n}(\%)$} \\
\hline II & 4/195 (2) \\
\hline III & $121 / 195(62)$ \\
\hline IV & 70/195 (36) \\
\hline LV ejection fraction, $\%$ & $44 \pm 16$ \\
\hline
\end{tabular}

$L V$, Left ventricular.

Seventy-four percent of patients had cardiomyopathy of any origin $(42 \%$ ischemic, $27 \%$ dilated, $5 \%$ valvular). Mean ejection fraction was $44 \% \pm 16 \%$ (range, $12 \%-77 \%$ ). Coronary artery disease was present in $72 \%$ of patients, and $35 \%$ had a history of coronary artery bypass grafting (CABG). Other cardiovascular risk factors included hypertension $(74 \%)$, renal failure $(52 \%)$, diabetes $(35 \%)$, and chronic obstructive pulmonary disease $(35 \%)$. Baseline patient characteristics are shown in Table 1.

\section{Percutaneous Mitral Valve Repair Procedure}

All MitraClip device interventions were performed as previously described. ${ }^{6,7}$ In brief, with the patient under general anesthesia and using fluoroscopic and transesophageal 2- and 3-dimensional echocardiographic guidance, the MitraClip device was advanced via the transseptal route across the mitral annulus into the left ventricle. With the 2 arms of the clip extended, the device was retracted to capture the anterior and posterior leaflet at the height of the regurgitant jet, and subsequently closed to approximate the mitral leaflets, thereby emulating the surgical edge-toedge technique introduced by Alfieri and colleagues. ${ }^{6}$ If the reduction in MR was inadequate with 1 device, the device was removed or a second device placed. Procedural success was defined as the implantation of at least 1 clip and residual MR of grade $2+$ or less.

\section{Follow-up}

Clinical and echocardiographic follow-up evaluation was scheduled at the time of hospital discharge and 12 months after the procedure. If a return visit was hindered by comorbidities, reevaluation was restricted to telephone follow-up. At clinical visits, transthoracic echocardiography was carried out and NYHA functional class was assessed. Postinterventional severity of MR was graded as previously described ${ }^{12,13}$ according to the technique of Foster and colleagues ${ }^{14}$ following the American College of Cardiology guidelines.

\section{Statistics}

Data are presented as mean \pm standard deviation or median plus (interquartile) range for continuous variables, and as counts and percentages for categoric variables. Continuous variables were compared by Student $t$ test. The Kaplan-Meier method was used for time-to-event analysis.

\section{RESULTS}

Median procedure duration, device time (from transseptal puncture to withdrawal of the clip delivery system from the left atrium), and fluoroscopy time were $180 \mathrm{~min}-$ utes (range, 60-560 minutes), 66 minutes (range, 15-395 minutes), and 28 minutes (range, 7-152 minutes), respectively. Percutaneous MVR was successful in 186 of 202 patients $(92 \%)$ as defined by MR of $2+$ or less (Figure 2 ). Thirty-day mortality was $3.5 \%$ (7/202 patients). The reduction in MR from pre- to postprocedure was significant $(P<.0001)$ and remained stable within the first 12 months in the majority of patients. In successfully treated patients, 60 had a reduction by $1 \mathrm{MR}$ grade $(30 \%), 104$ had a reduction by 2 MR grades $(52 \%)$, and 26 had a reduction by 3 MR grades $(13 \%)$. In 12 patients $(6 \%)$, no reduction in MR could be achieved (Figure 3). A single clip was implanted in 125 patients $(62 \%), 2$ clips were implanted in 64 patients $(32 \%)$, and 3 or more clips were implanted in 7 patients $(4 \%)$. In 16 patients $(8 \%)$, clip implantation was not achieved $(n=6)$ or did not reduce MR to less than grade $3+(n=10)$.

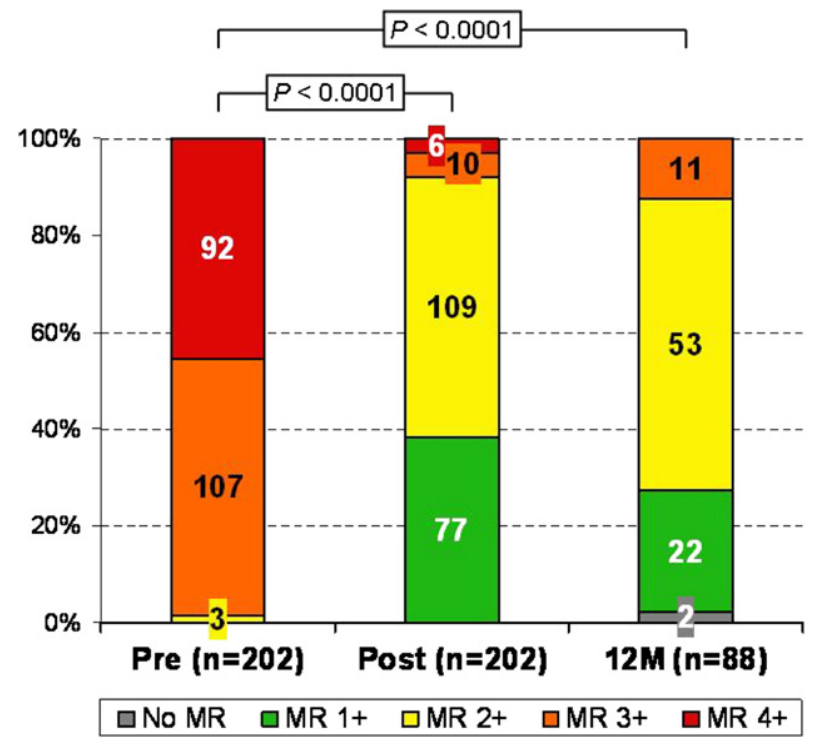

FIGURE 2. MR at baseline, postprocedure, and 12 months after interventional MVR using the MitraClip device (Abbott Vascular, Menlo Park, Calif) $(P<.0001$, chi-square test $) . M R$, Mitral regurgitation. 


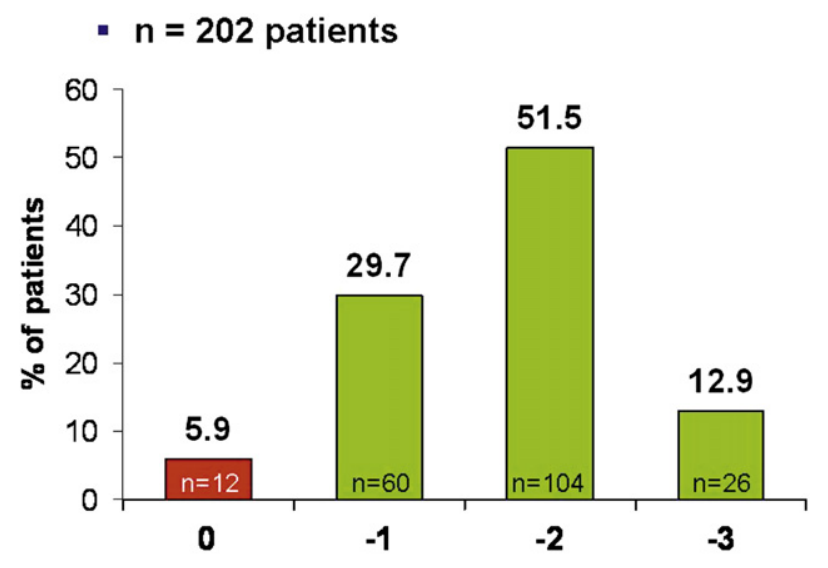

Acute MR reduction by grades

FIGURE 3. Acute reduction in MR from baseline to postprocedure after interventional MVR using the MitraClip device. Mean: $-1.7 \pm 0.8$, $\mathrm{n}=202 . M R$, Mitral regurgitation.

Echocardiographic data did not reveal a difference in left ventricular end-diastolic and end-systolic diameters from baseline to 12 months.

Data on preprocedural tricuspid regurgitation (TR) were available in 193 patients. Of those, only $20.2 \%$ presented with a concomitant TR grade of 3 or greater. In the group of patients with 12 months echocardiographic data on TR $(\mathrm{n}=66)$, the majority $(53.1 \%)$ did not show any change in degree of TR or even decreased TR $(17.1 \%)$, whereas $29.7 \%$ showed an increase of TR by $1(25.0 \%), 2$ $(3.1 \%)$, or $3(1.6 \%)$ grades.

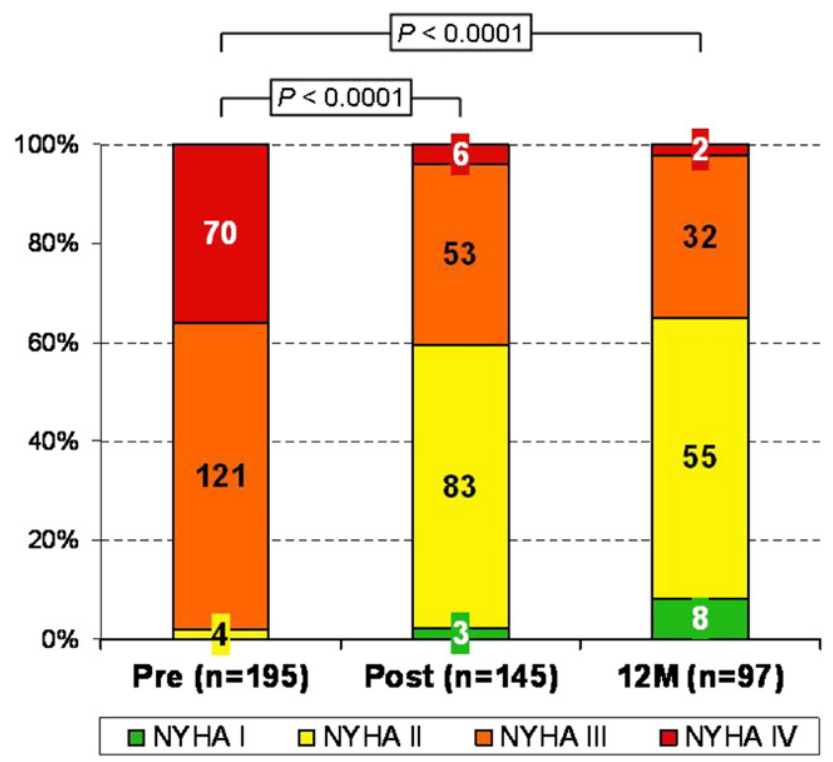

FIGURE 4. Change in NYHA functional class from baseline to discharge and during 12 months follow-up after interventional MVR using the MitraClip device $(P=.0001$, chi-square test). NYHA, New York Heart Association.

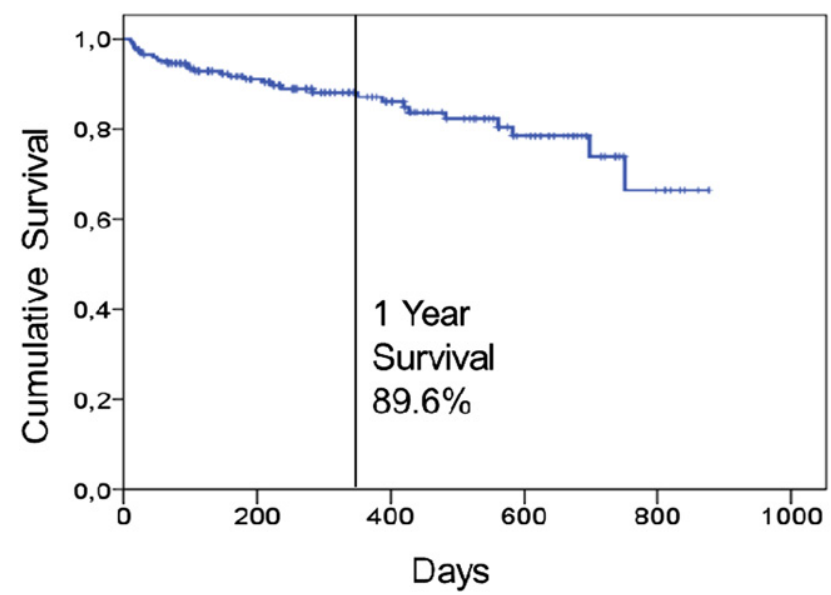

FIGURE 5. Cumulative survival after interventional MVR using the MitraClip device (Kaplan-Meier analysis).

Patients were less symptomatic after MitraClip device implantation as expressed by a significant reduction in NYHA functional class $(P<.0001)$ after the procedure and during follow-up (Figure 4). Mean acute reduction in NYHA classification was $-0.9 \pm 0.7$. At hospital discharge, $74 \%$ of patients showed an improvement in NYHA class of at least 1 class. The proportion of patients in NYHA class I or II at discharge and after 12 months was $59 \%$ and $65 \%$, respectively (Figure 4). Overall survival at 12 months was $89.6 \%$ (Figure 5).

Patients were hospitalized for a median of 9 days (range, 1-73 days). Kaplan-Meier estimation revealed a 1-year survival of $89.6 \%$ (Figure 5).

Eleven patients required surgical reintervention because of failed repair $(n=3)$ or recurrent severe $\mathrm{MR}(\mathrm{n}=7)$, or despite good valve function $(\mathrm{n}=1)$ at a median of 38 days (range, 0-468 days) after MitraClip device implantation. Six patients underwent operation at the University Heart Center. ${ }^{15}$ Five patients underwent MVR, and 6 patients had mitral valve replacement using biological prostheses. Injury of the mitral leaflets caused by prior MitraClip device treatment was present in 6 patients, influencing the surgical strategy toward more complex repair techniques in 3 patients and mitral valve replacement in 1 patient. Figure 6 shows typical clip-related lesions after intraoperative clip detachment with leaflet defects and chordal ruptures. Both valves were repaired successfully despite structural defects. All patients undergoing operation after failed MitraClip device implantation at the University Heart Center are alive with adequate valve function at the latest follow-up of $9.8 \pm 7.3$ months (range: 1-19 months). Five patients underwent operation at outside hospitals after MitraClip device implantation, and 2 of them died of unknown reasons in hospital after mitral valve replacement. One patient underwent combined CABG and MVR despite good valve function (MR 1+) at an outside hospital 58 days after clip implantation. 

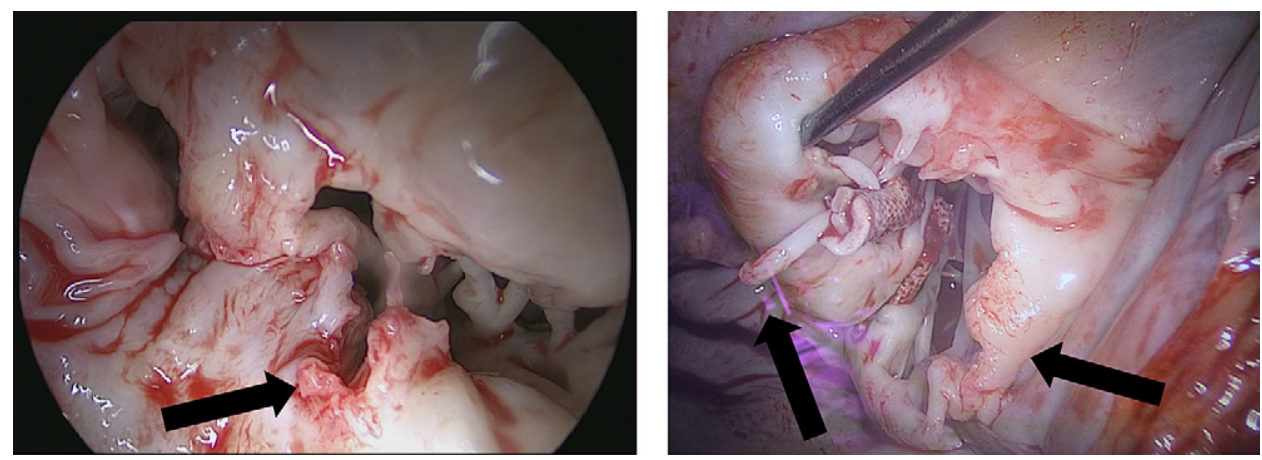

FIGURE 6. Clip-related lesions at the anterior and posterior mitral valve leaflets with chordal rupture (arrows). Both valves were repaired successfully.

\section{DISCUSSION}

In patients with severe MR deemed at high risk for surgery, percutaneous MitraClip therapy proved to be a safe and acceptably effective alternative to surgical MVR. Acute reduction in MR by 1 grade or more in $92 \%$ of patients led to an improvement in NYHA functional class in the majority of patients (60\% NYHA class I or II at discharge, $72 \%$ at 1-year follow-up). On the other hand, only $38 \%$ of patients at discharge and $28 \%$ at 12-month follow-up achieved a post-interventional MR grade of $1+$ or less, which would be accepted as a result after surgical repair. Degree of TR was not or positively affected by MitraClip therapy in $70.3 \%$ of patients, whereas an increase of TR developed in $29.7 \%$ of patients within 12 months follow-up. The study is limited by the fact that 12-month echocardiographic follow-up was available in only 88 patients; therefore, unbiased interpretation of long-term data is not possible at this time. Nevertheless, patients benefited from a safe and less-invasive procedure. Although 30-day mortality was only $3.5 \%, 1$-year mortality was $10.4 \%$, reflecting the reduced state and the complex morbidity of the patients.

In comparison with the recently published EVEREST II trial, ${ }^{9}$ our patients reflect a different patient cohort. In the MitraClip arm of EVEREST II, 73\% of patients had degenerative disease and $49 \%$ were in NYHA class I or II, whereas $73 \%$ of our patients had functional or mixed MR and $98 \%$ were in NYHA class III or IV. Eighty percent of our patients would have fulfilled the exclusion criteria for the EVEREST II trial.

In EVEREST II, MitraClip-treated patients benefited from lower complication rates at 30 days, yet by 1 year, $20 \%$ of those patients required surgical MVR because of recurrent or persistent severe MR. In addition, $46 \%$ of patients showed post-interventional MR $2+$ or more. The only modest reduction in MR severity might be associated with favorable short- and midterm outcomes, but surgical series suggest that residual MR predicts adverse longterm clinical outcomes. It is for this reason that we do not offer percutaneous MVR to low-risk patients at the University Heart Center. Moreover, the intention-to-treat analysis of the EVEREST II trial showed that patients with functional MR, aged more than 70 years, or with a left ventricular ejection fraction less than $60 \%$ might particularly benefit from percutaneous MVR. This particular subgroup of patients should be evaluated for percutaneous MVR after thorough evaluation by a dedicated heart team, although it is obvious that, like surgery, the clip cannot treat the underlying ventricular disease.

Eleven of our 202 patients ( $5 \%$ ) required surgical MVR or replacement after percutaneous repair because of failed procedure or insufficient MR reduction. One patient underwent combined CABG and surgical MVR despite good valve function after MitraClip device implantation. Patients undergoing operation at the University Heart Center survived the procedure and showed good clinical outcome despite elevated surgical risk. Nevertheless, 2 patients undergoing operation at an outside hospital died during the hospital stay, underlining the fact that postinterventional mitral valve surgery is even more complex and should be performed by experienced mitral valve surgeons only. Surgery was complicated but not impeded by previous clip implantation, although MVR was only possible in 5 patients and the other 6 patients underwent mitral valve replacement with biological prostheses. Even in high-risk patients, surgical treatment remained an option and proved to work as a successful "bail-out" therapy for failed MitraClip repair. High surgical risk does not necessarily translate into inoperability.

In contrast with concerns of many cardiac surgeons, the implementation of a percutaneous mitral valve program did not have a negative influence on our center's surgical mitral valve volume. To the contrary, the surgical volume even increased because of a positive impact of patients who were referred for interventional treatment but turned out to be good surgical candidates and therefore consequently underwent surgical MVR (Figure 7).

\section{CONCLUSIONS}

Given an aging population and a steady increase in cardiovascular diseases including functional mitral valve 


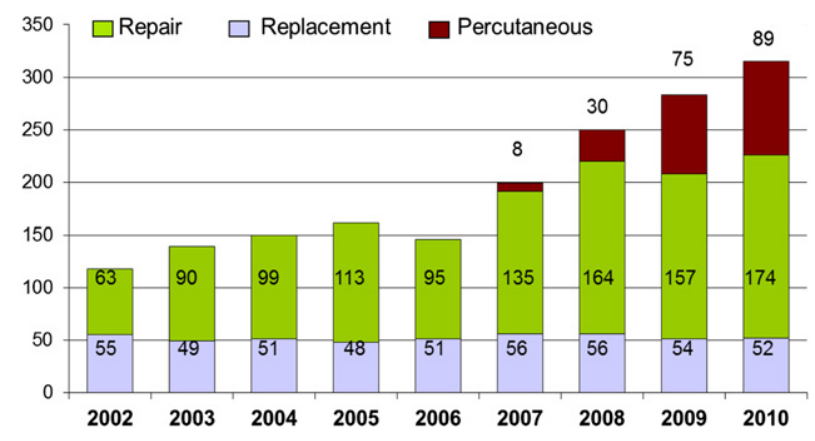

FIGURE 7. Volume of surgical and percutaneous mitral valve treatment at the University Heart Center Hamburg 2002-2010.

regurgitation, the need for less-invasive mitral valve therapies is evident. Interventional cardiologists and cardiac surgeons as a heart team have the knowledge and understanding of mitral valve pathology and repair techniques. It seems only natural that any technique of interventional MVR should be performed in close collaboration and after detailed discussion among the heart team. As members of the team, cardiac surgeons should now consequently take the chance to adopt these new techniques and make them part of their portfolio.

\section{References}

1. David TE, Ivanov J, Armstrong S, Rakowski H. Late outcomes of mitral valve repair for floppy valves: implications for asymptomatic patients. J Thorac Cardiovasc Surg. 2003;125:1143-52.

2. Bonow RO, Carabello BA, Chatterjee K, et al., American College of Cardiology/ American Heart Association Task Force on Practice Guidelines. 2008 focused update incorporated into the ACC/AHA 2006 guidelines for the management of patients with valvular heart disease: a report of the American College of Cardiology/American Heart Association Task Force on Practice Guidelines (Writing Committee to revise the 1998 guidelines for the management of patients with valvular heart disease). J Am Coll Cardiol. 2008;52:e1-142.

3. Conradi L, Treede H, Deuse T, Brickwedel J, Detter C, Reichenspurner H. Minimally-invasive mitral valve surgery: evolution of the technique to the standard of care for mitral repair. Thorac Cardiovasc Surg. 2010;58:S119.

4. Bach DS, Bolling S. Improvement following correction of secondary mitral regurgitation in end-stage cardiomyopathy with mitral annuloplasty. Am J Cardiol. 1996;78:966-9

5. Mirabel M, Iung B, Baron G, et al. What are the characteristics of patients with severe, symptomatic, mitral regurgitation who are denied surgery? Eur Heart J. 2007; $28: 1358-65$

6. Alfieri O, Maisano F, De Bonis M, et al. The double-orifice technique in mitral valve repair: a simple solution for complex problems. J Thorac Cardiovasc Surg. 2001;122:674-81.

7. Feldman T, Wasserman HS, Herrmann HC, et al. Percutaneous mitral valve repair using the edge-to-edge technique: six-month results of the EVEREST Phase I Clinical Trial. J Am Coll Cardiol. 2005;46:2134-40.

8. Feldman T, Kar S, Rinaldi M, et al. Percutaneous mitral repair with the MitraClip system: safety and midterm durability in the initial EVEREST (Endovascular Valve Edge-to-Edge REpair Study) cohort. J Am Coll Cardiol. 2009;54: 686-94.

9. Feldman T, Foster E, Glower DG, et al. Percutaneous repair or surgery for mitral regurgitation. $N$ Engl J Med. 2011 Apr 4 [Epub ahead of print].

10. Zoghbi WA, Enriquez-Sarano M, Foster E, et al. Recommendations for evaluation of the severity of native valvular regurgitation with two-dimensional and Doppler echocardiography. J Am Soc Echocardiogr. 2003;16:777-802.

11. Nashef SA, Roques F, Michel P, Gauducheau E, Lemeshow S, Salamon R. European system for cardiac operative risk evaluation (EuroSCORE). Eur J Cardiothorac Surg. 1999;16:9-13.
12. Franzen O, Baldus S, Rudolph V, et al. Acute outcomes of MitraClip therapy for mitral regurgitation in high-surgical-risk patients: emphasis on adverse valve morphology and severe left ventricular dysfunction. Eur Heart J. 2010;31: 1373-81.

13. Franzen $O$, van der Heyden J, Baldus S, et al. MitraClip(R) therapy in patients with end-stage systolic heart failure. Eur J Heart Fail. 2011;13:569-76.

14. Foster E, Wasserman HS, Gray W, et al. Quantitative assessment of severity of mitral regurgitation by serial echocardiography in a multicenter clinical trial of percutaneous mitral valve repair. Am J Cardiol. 2007;100:1577-83.

15. Conradi L, Treede H, Franzen O, et al. Impact of MitraClip therapy on secondary mitral valve surgery in patients at high surgical risk. Eur J Cardiothorac Surg. 2011 Apr 14 [Epub ahead of print].

\section{Discussion}

Dr A. Marc Gillinov (Cleveland, Ohio). That was an excellent and timely article. You present results in 202 patients receiving the MitraClip device. Your 30-day mortality was only $1 \%$. The mean decrease in MR grade with the procedure was 1.7 , and, remarkably, at 1 year, $72 \%$ of surviving patients are in functional class I or II. So I will ask you 3 fairly straightforward questions, that is, who, how, and when.

First is the who question, and that is the most important. You have described the patients who are treated, who they are, and how you get to them. It looked to me from the article, which you were kind enough to provide, that it tends to be people with functional MR who have often undergone previous cardiac surgery. My main question with "who," though, is this: As your experience has increased and you have developed a greater comfort zone, are you seeing the indications creep into the surgical population? Are you seeing more patients in whom you would say, we could operate on him, but let's try percutaneous first?

Dr Treede. Actually, that is not the case. We do not switch our indications. We still perform surgery in all patients who are operable, and we have no reason to change this unless the results of surgery are still better than the results of the MitraClip therapy in terms of reduction of MR, and because we know the data published by Sarano and colleagues that patients with remaining MR 2+ don't do as well in the long-term follow-up compared with patients without MR. So this should be the reason not to switch indications. Especially in patients with organic MR, myxomatous disease, or even Barlow valves, the MitraClip device will probably come to its limits.

Dr Gillinov. The second question is how, not how do you do the procedure, but how should we judge success of the procedure? There seem to be 2 ways in which people judge the percutaneous repair. One is, how did we do with the MR, and the other is, how are the patients doing in terms of with functional class? For the MR, you declare procedural success if the MR is $2+$ or less, but I note that at 1 year, only $28 \%$ of patients have MR that is $1+$ or less (a surgical success). That doesn't sound very good. But, on the other hand, with approximately three quarters in NYHA class I or II, you could say the procedure is successful for the patient. How should we judge success?

Dr Treede. I would still suggest that we judge success by the grade of MR, because NYHA class is a subjective thing, and it is dependent on other variables (eg, medical therapy) that are not this measurable. So if we clearly stick to the echo data, we will find out what proportion the MitraClip therapy has on that better functional result. So I would still do that, although it is not this 
easy to judge MR after MitraClip therapy, because the double orifice may complicate echo measurements.

Dr Gillinov. The final question is when. When should we operate if the clip has not worked? Clearly you get scar tissue and ingrowth, and the surgical repair will be more challenging months down the road. Given what you know now, would you recommend to us to operate early if the patient leaves the catheter laboratory with 3+ MR?

Dr Treede. Yes, we have seen that it is harder to get the clip out once it is really ingrown into the valve. On the other hand, I would still make the decision dependent on the degree of MR, and I would not prophylactically operate on a patient who does not have severe regurgitation after the clip treatment. But once you have a severe regurgitation and the clip did fail, then it is definitely easier to do the operation earlier.

Dr Gillinov. Thank you. That was excellent.

Dr Gorav Ailawadi (Charlottesville, Va). I commend you on doing this important study. Can you give us more insight on those 11 patients who required a mitral operation as to the number of clips that were inserted and if that affected the ability to repair the valve? What was the risk in those 11 patients? You mention an $18 \%$ mortality. Do you have an idea of what their euroSCORE or Society of Thoracic Surgeons' risk was before determining placement of a MitraClip device?

Dr Treede. These were all in patients with a high euroSCORE, but as you know, a high euroSCORE does not mean that they are, by definition, inoperable, so we were able do the operations. Unfortunately, we do not have too much information on those patients who died after surgery, because they died in outside hospitals.

We cannot say with regard to the small numbers right now if the number of clips has any influence on the surgical outcome. One can, of course, assume that more clips would probably do more harm to the mitral valve, but having operated on some of them myself, I can say that the injury that the clip leaves at the leaflets is, in most cases, not so harmful that the valve is no longer repairable. So I cannot answer this part of the question right now.

Dr Robert Dion (Genk, Belgium). I am impressed by your pioneering work, but I have a few questions. First, you evaluate the results by considering the amount of residual MR or the NYHA class. But what about the remodeling of the left ventricle (the dimensions and volumes), how did it evolve with the time? Indeed, in principal, I have an objection to call a success a residual grade 2 MR in functional MR. Maurice Sarano has shown that even moderate MR has a deleterious influence on survival when LV function is altered. Therefore, I think you should select the patients who are absolutely inoperable, because you leave most of them with a grade $2 \mathrm{MR}$, which is again not innocuous in a bad ventricle.

My second point is that you say the mortality is approximately $1 \%$. But we have heard that it can increase to $18 \%$ when a patient has to undergo reoperation after a failed clip.

Dr Treede. We are absolutely of your opinion, and we would still only include patients in the MitraClip program who are at high risk for surgery but probably not completely inoperable, because inoperability has another aspect. Once you have done the MitraClip placement and see an increase in MR, then you should probably have a way to treat the patients afterward. If the patients are completely inoperable, it is hard to include them in the program because we would no longer have an exit strategy for a patient in whom the clip has failed or even does harm to the valve.

The 2 patients dying after surgery because of failed implantation died in an outside hospital. It is hard for us to judge if that was due to surgeons who did not have much experience with mitral valve operations. I would definitely suggest and strongly recommend that only very experienced mitral valve surgeons perform reoperations in patients after the clip. So this is at least something we would recommend. I don't think that $18 \%$ is the true mortality for patients undergoing surgery after clip implantation. 